\title{
Modes and Dimensions of Being
}

\author{
David Alvargonzález ${ }^{1}$ (1)
}

Received: 22 June 2021 / Accepted: 5 September 2021 / Published online: 17 September 2021

(c) The Author(s) 2021

\begin{abstract}
In this paper, I put forward a theory about the modes and dimensions of being. In the first section, I define existence through coexistence, understood as the codetermination of certain things and processes via other things and processes. In the second section, I differentiate between modes and dimensions of being. In the third section, I argue that the modes of existing are the different ways in which coexistence and codetermination take place and discuss two types of modes ("fundamental" and "categorial"), to subsequently present a classification thereof. In the fourth section, I posit a theory about the dimensions of any existing thing or process, arguing for the existence of two types of dimensions: configurational and processual.
\end{abstract}

Keywords Being $\cdot$ Mode $\cdot$ Category $\cdot$ Dimension $\cdot$ Hylomorphism $\cdot$ Reality

\section{The Idea of Being}

Arising as an idea in Greek philosophy, the idea of being took complete shape in Parmenides, Plato and Aristotle and has spanned the entire history of philosophy up to 20th-century existentialism and the present-day modal doctrines. Here, my purpose is to analyze the structure of this idea by classifying the different varieties of existing things and processes and proposing a theory about the basic dimensions of being.

Throughout this article, I make a distinction between "metaphysics" and "ontology". I use "metaphysics" to refer to a manner of understanding ideas as something substantial and given independently from existing things and processes. In the Platonic Academic tradition, changeless forms are supposed to exist "apart from", "separated from" and "over and above" existing and changing things. I use "ontology"

David Alvargonzález

dalvar@uniovi.es; davidalvargonzalez@gmail.com

https://filosofia.uniovi.es/personal/-/asset_publisher/OJ17/content/pdi_alvargonzalez-david;

jsessionid=C0B599F2297E76B9748F618D9CCA2476? redirect=\%2Fpersonal

1 Department of Philosophy, University of Oviedo, Teniente Alfonso Martínez, s/n, 33011 Oviedo, Spain 
to refer to the philosophical discipline studying specific ideas that affect reality, itself considered in the most general way possible (the ideas of being, unity, identity, necessity and possibility, among others), but on the understanding that such ideas only exist as incarnate in the world. In this way of understanding ontology, metaphysics is a specific (spiritualist, monist, transcendent) variety of ontology. Aristotle's Metaphysics includes an ontology — a theory of being in general — and a metaphysical theology - a theory of God. His theology studies the Unmoved Mover as an eternal, immoveable, non-sensitive, indivisible, incorruptible, impassive, unalterable, active, changeless, transcendent living being without magnitude or parts and detached from sensible substances (Metaphysics XII, 6-9). As the theory of divine being, theology clearly plays a major role in Aristotle's philosophy since God, the Unmoved Mover, is postulated as the most perfect mode of existence, as the strictest and most precise variety of primary being, as the most worthy kind of being (Metaphysics VI, 1026a 19-21). Under this optic, Aristotle's idea of God is eminently metaphysical.

I hold that the idea of being need not be either metaphysical or theological and does not involve the existence of a transcendent being, just as the idea of unity does not necessarily involve ontological, transcendent monism. Rather, I assume that the idea of being, like many other ideas, derives from practical knowledge, for since immemorial time humans have had to render judgments about what it means for a certain thing or process to exist and about the different modes in which things and processes exist. As such, the idea of being does not derive from nor is it mainly determined by a supposedly transcendent, divine substance, but rather from and by effective, existing beings. Further, the ideas of existence and being are syncategorematic ideas, since "being" and "existing" are always the being or existing "of something". Indeed, many other syncategorematic ideas have been widely discussed philosophically in a non-metaphysical manner, such as the ideas of unity, identity, purpose, freedom, sense and conscience, among others.

This paper takes as a guiding principle the assumption that something's existence always involves its coexistence. This is tantamount to denying the absolute existence of a separate and self-determined being, stretching beyond Aristotle's God, Leibniz's windowless monads and Avicenna's flying man to include Aristotle's primary beings, which he defined as ontologically separate, as being in virtue of themselves (Metaphysics VII, 1, 1028a 33-34). In my view, absolute ontological independence is a metaphysical idea, since existing is always coexisting with other terms, is always coexisting at a certain time and place.

I also assume that coexistence exhibits a non-connected, universal relationship, where "universal" means that it distributively applies to everything existent and "non-connected" that it gives rise to connections and disconnections of things and processes forming different groups. Geometric parallelism provides an example of a non-connected, universal relationship, since every line in a given set of lines maintain a parallel relationship with others, but their different directions trigger the formation of different subsets of parallel lines, each characterized by a specific direction. Plato advocated for non-connected codetermination between entities and processes when putting forward the idea of symploké (Sophist 252e, 259e), wherein mutual determination unites as much as it separates since it involves both 
the connection and the disconnection of certain parts from others. I will show that these different bundles of relationships, connections and mutual determinations are but the various modes of existing as coexisting.

Assuming that the ideas of coexistence and codetermination lie at the core of the idea of being, I posit that this nucleus is internally modulated in such a way as to give rise to a functional idea that it is neither a simple equivocal conglomerate nor a merely incoherent collection. The attempt to classify the different ways of existing is but the recognition that, as Aristotle stated, "being" can be said in many ways (Metaphysics IV, 2. 1003a). However, Aristotle's idea of being did not support this internal modulation, since God was a changeless, incorruptible, immobile, non-sensitive, separate and transcendent living being. As such, he concluded that being was homonymous, although he admitted that he presented a sui generis homonymy, a "non-random homonymy" (Nicomachean Ethics 1096b).

At any rate, in the idea of existence as coexistence, there are parallels with other ideas, such as the idea of operation: philosophical analysis is not about constructing the experience of existence or the exercise of the operations. Our ordinary experience of existing things and our exercise of specific operations are pre-philosophical. Ontology is thus about analyzing the idea of existence and not about constructing existence.

\section{The Distinction Between Modes and Dimensions of Being}

The idea of existence as coexistence entails the constant codetermination between existing things and processes. Accordingly, the modes of being depend on the different modes whereby the connections and disconnections found in those codetermination processes are given.

The Oxford English Dictionary defines "mode" as "a particular way of doing something; a particular type of something" and "a way or manner in which something occurs or is experienced, expressed, or done". In the field of logic, mode is "the character of a modal proposition (whether necessary, contingent, possible, or impossible)." The Cambridge English Dictionary defines "mode" as "a way of operating, living, or behaving; a manner of doing something; a kind or type". Thus, the lexical definitions of "mode" always include the meaning of modifying something within certain limits so that it is still what it is.

In common language, the word "dimension" means "an aspect or feature of a situation". When used as a scientific and technical concept, dimensions are always characterized by being able to vary independently of each other, despite their inseparability. In this paper, I differentiate between "separating" and "dissociating", holding that something is separable when disconnection from a given environment is possible, although separation is not absolute since it involves connection with another different environment. The possibility of relatively separating an object or process from its environment does not mean that it can have an existence wholly disconnected from the rest of the world. An animal is separable from a given territory if it can be moved to another territory that constitutes an ecosystem where it is viable. Absolute 
disconnection is not compatible with this idea of existence as coexistence and codetermination. Aristotle's God exemplifies a metaphysical separable being.

However, there are configurations that do not support separation. An example taken from language is the days of the week, since the definition of each day means that it is inseparable from the previous and subsequent days: Tuesdays are inseparable from Mondays and Wednesdays. In biology, the human nervous system is inseparable from the rest of the body since something like "a brain in a vat" (in Putnam's famous thought experiment) is not biologically viable. Aristotle first discerned the impossibility of separating certain parts of living organisms (Metaphysics VII, 10, 1035b 20-25). Dissociation is an abstract separation to account for specific configurations that follow rhythms other than those of their environment, notwithstanding their material inseparability. The differentiation of an organism's systems (nervous, digestive, respiratory, reproductive, circulatory, etc.) bears this significance, in that these systems are functional units, even though they cannot have a separate existence. Aristotle refers to certain attributes deemed inseparable from the subject of predication, specifically citing sexed animals and saying that there are no males or females separated from the fact of them being animals (Metaphysics XIII, 3, 1077b21-1078a31).

This also happens in all contexts in which time is abstracted. The radical separation of any configuration outside time is impossible since existence involves coexistence and codetermination, which requires time and succession. When something that is materially inseparable is considered as separated, then metaphysical substantialization takes place. Such is the case for Plato's ideas understood as forms separated from the world, the Aristotelian absorbed God and Putnam's biological impossibility of a brain in a vat.

In this paper, I understand dimensions as inseparable but dissociable, assuming that they are neither parts nor components in the sense of separable parts, even though we can dissociate and segregate them abstractly for specific purposes. When analyzing real processes and configurations based on their dimensions, one can find independent rhythms, and those rhythms can be dissociated from each other, on the understanding that they are inseparable when relating to the actually existing beings. For instance, in the three dimensions of Euclidean space, mathematicians dissociate flat geometry, with its polygons and curves; this does not entail the existence of a real, two-dimensional world. A flat world, as imagined by Edwin A. Abbott in his novel Flatland, is impossible and cannot really exist (Abbot [1884], 2017).

\section{The Modes of Being and Their Classification}

As already stated, I understand existence as coexistence and codetermination and, consequently, the modes of the idea of being depend on the various modes whereby the connections and disconnections found in those codetermination processes are given. I distinguish two types of modes: fundamental and categorial. Fundamental modes are characterized in that they apply distributively to everything existing: something existing has to be in the present, past or future, it has to be necessary or contingent and it has to be real or fictitious. On the contrary, categorial modes of 
being are regional and specific to certain areas of reality. These include the manner of biological, mathematical, physical, political, psychological and literary being. At this juncture, I do not understand the idea of category in Aristotle's sense but in the sense coined by Gustavo Bueno, as it will be defended below (Bueno 2013). Fundamental modes of being cut across all categories, thus making it possible to bring the two classification criteria together to form a matrix that includes the fundamental modes of existing as they are specified in each of the categories.

I assume that the modes of the idea of being as they appear in the human languages of words (de dicto modes) are but a special modulation (be it logical, grammatical, verbal) of the modes of the idea of being as they occur in the world of things and processes (de re modes). This means that ontology cannot be reduced to the study of judgements, propositions or intensional concepts: language is an important part of reality and is key to ontology (and, in general, to philosophy), but the modes of being refer mainly to extralinguistic realities.

\subsection{Classification of the Fundamental Modes of Being}

Defining the core of the idea of existence as coexistence and codetermination involves the connection and disconnection between things and between processes. Focusing on these connections, I propose three criteria to classify the fundamental modes of existing.

The first distinguishes three modes based on the symmetry or asymmetry of those connections. When symmetrical interaction between the coexisting is possible, we then speak of the "here and now" or of what is given in this present moment. When relationships are asymmetrical, there are in turn two possibilities: being influenced without the possibility of influencing (such is the definition of the past) and influencing other entities without the possibility of being influenced by them (which defines the scope of the future).

The second criterion focuses on the possibility of disconnecting existing things or processes. When disconnection is possible, processes and things are contingent; otherwise, they are necessary.

The latter classification criterion focuses on the very nature of the connections: when there are effective causal connections, they fall into realm of the real; those connections are regarded as fictional when they are merely depicted or narrated.

\subsubsection{Modes of Existence According to the Symmetry or Asymmetry of the Coexistence Relationships}

The main function of the present tense in many modern languages is to mark the immediate mode of existing, i.e. being as something currently existing, as something present at the same time as our utterance. This is the foremost case in which something coexists with and codetermines other entities and processes.

At any rate, present-day existing does not in itself hold all the keys to its own intellection, since certain essential components are unintelligible without reference to the past and to the coming future. I contend that there is no absolute, initial, 
primitive or pristine present removed from any antecedents. In addition, I hold that the future must be considered in any purported understanding of any other significant part of what currently exists, since there is no "eschatological" present, no present without posterity (Bueno 2010).

Using memory, animals know about things that existed in the past and that are no longer present due to their transformations. Among humans, past tenses enable us to refer to such things and processes; some of them are definitively finished, "perfected" insofar as they are irrevocable. The practical significance of the past grows evident to the extent that what happened in the past makes its presence felt in the present. Together, these two modes of being (past and present) comprise a core component of our idea of causality and its anthropological modulations of responsibility and guilt. Sciences make it possible to reconstruct specific aspects of the past beyond the horizon of psychological memory: geology, natural history, archeology, prehistory and political history, to cite but the most relevant.

In organisms with purposeful behavior and especially in the anthropological field where human word languages exist, the virtual, the future, the possible and the potential are ways to refer to the existing. The future is that which the present can influence but which cannot effectively influence the present. Memory of the past, which forms part of biological organisms' learning processes, lies at the core of the processes involving purposeful teleology (prolepsis as anamnesis).

The sociologist Alfred Schütz characterized the social past, present and future in terms of asymmetry of relationships similar to those I have used here. Schütz argued that our predecessors influence us without us being able to influence them and that we influence our successors without them being able to influence us. However, we cannot interact with our successors since interaction is only possible with our contemporaries (Schütz 1932, 1962), , . My criterion takes this idea from Schütz, which refers only to human subjects, and generalizes it to all manner of objects, subjects and processes in the world.

In this, the present is not univocal: there is a multiplicity of presents since the radii of coexistence and codetermination varies significantly depending on the nature of the connections considered in each case. The geological present is marked by the quaternary period. Politically and internationally, the present is often linked to the fall of the former Soviet Union; as Lewis Mumford holds, the technological present was distinguished by the neotechnical stage (Mumford 1934); for Christians, the present of universal history starts with the coming of Christ, while for Muslims it begins with Muhammad.

\subsubsection{Modes of Existence Based on the Possibility of Disconnecting Coexisting Things}

Among the entities and processes existing in reality, a distinction should be drawn between those that are necessary and those that are contingent. Existence understood as coexistence is basically a contingent existence since the other things and processes serving as a reference may change and, in any case, the observer herself is continuously changing. 
On the contrary, the necessary mode of being is that which cannot be otherwise. I posit that there are apodictic, objective relationships independent of the subjects in the regional fields of the strict sciences. Certain well-known examples could be cited. In Euclid's geometry, the angles of every triangle necessarily add up to 180 degrees; the physical-chemical sciences assume that a piece of solid iron is denser than water and, therefore, necessarily sinks; the biological sciences assume that human organisms are necessarily mortal. This essential scientific necessity is the most proper, but not the only way of understanding it. In practical contexts, specific circumstances may be necessary to achieve a given purpose. At any rate, recognizing the necessary processes and configurations in science does not mean that the composition of necessary processes in different sciences gives rise to new necessary configurations since the nexus of such composition can be contingent. The opposite of the necessary is the non-necessary, the contingent. What is necessary is not defined vis-à-vis what exists, as Kant supposed ( $K r V$, A 218/B265): existence is not a mode of being but rather is the core of the very idea of being, which is none other than coexistence (Kant 2007).

Just as the idea of existence implies coexistence, the idea of possibility implies the compossibility of something with respect to other terms or processes we take as a reference. Possibility and impossibility are objective since they depend on the nature of the connections between things and processes and not on the subject. In the Metaphysics, Aristotle argued that not everything is possible (Metaphysics IX, 4, $1047 \mathrm{~b}$ and ss.), defining the impossible (adynaton) as "that whose opposite is necessarily true" (Metaphysics V, 1019b, 24-25) and the possible as that "whose contrary is not necessarily false" (Metaphysics V, 3, 1047a24; Posterior Analytics 32a18-20). Thus, necessity is what clearly marks the realm of what is actually impossible: contradiction is logically impossible; the commensurability of a square's side and the diagonal is geometrically impossible; it is physically impossible for baryonic matter to be weightless; and incorporeal organisms, composed of radiation alone, are biologically impossible. As will be seen, the impossible is always categorially determined, be it logically, mathematically, physically, biologically, etc. Anselmian metaphysics and modern rationalism (Descartes, Leibniz) sought to derive a real possibility and necessity (physical, biological, ontological) from logical possibility and necessity. However, possibility is not a purely formal matter, as Kant assumed when he defined it as "what corresponds to the formal conditions of experience (from the point of view of intuition and concepts)" (Kant $K r V$, A 218/B265.). This logical, formal possibility does not immediately involve a geometric, physical or biological possibility. Stephen Toulmin held that logical possibility by itself is insufficient, since it only enables a kind of prior evaluation to verify that sentences have significant coherence. As Toulmin holds, possibility must always refer to certain specific regional areas: biological, physical, legal or ethical (Toulmin 1958, 169-177).

Potentiality is not exactly the same as possibility, since it is not mere compatibility with existence but involves a sui generis, categorially specified capacity. Scientific categories (with their theorems and principles) mark the limits of what potentially exists, such as the biological potentiality of the acorn to give rise to an oak or the anthropological potential of the human individual to speak a language of words. For Aristotle, potentiality is the ability to produce a specific change, the ability to be 
in a different and more complete state (Metaphysics 1048b1-3). W.T. Stace argued that Aristotle's idea of potentiality is meaningless: “"potentiality” is not an experienceable feature of anything. It is a concept without any application in every conceivable experience. And, therefore, it makes no sense" (Stace 1935, 428). While Stace is right in stating that potentiality is not a directly experiential phenomenon, that does not mean that it is always a metaphysical idea disconnected from certain phenomena of experience or that it has no application. As already mentioned, biologists know that the embryos of each species have the potential to become adults of that specific species.

\subsubsection{Modes of Existence According to the Nature of the Links of Connection}

The existence of certain things and processes that are invented, narrated, depicted, sculpted, filmed, etc. elicits another distinction between two radically different modes of being: the real and the fictional. Aristotle repeatedly found the word "man" to be an illustration of equivocal homonymy when used to refer to the real and the depicted man, holding that Plato's ideas did not bear the same reality as the things and processes of the sublunary world since the idea of a horse does not whinny, the idea of knowing does not know and the idea of movement does not move (Metaphysics IX, 8, 1050b20-1051a2). In addition, he frequently distinguished the mode of being of things themselves from the mode of being when it relates to the truth or falsity of statements (Metaphysics, V, 7, 1017a22-35). Predication, narration, painting or sculpting are allegorical exercises and originally relate to the (narrated or depicted) predicated reality. When these inventive activities start to work in disconnection from reality, then they may produce monsters, myths and metaphysical ideas. From the first representations of therianthropes in Paleolithic caves to the metaphysical God of theology, fantastic beings created by accreting features of different animals and humans have abounded. The breadth of fiction thus ranges from the construction of plausible entities and processes to the unrestrained fantasy.

Yet, stubborn reality follows its own rhythms independent of the subject's will. Fiction is not nothingness, though, but rather something thought of as related to reality and etiologically connected with it in two opposite ways. On the one hand, there is a connection between fiction and the real, since real beings produce fiction. On the other hand, fiction can also be the cause of specific real processes as happens with legal fiction, myths and fake news: the famous forgery of the Donation of Constantine stands as an example of a fiction that had real consequences in the thirteenth century by supporting the papacy's claims of political authority.

\subsection{The Categorial Modes of Being}

Once the real has been defined as coexistence and codetermination, drawing the distinction of categorial modes of being helps to answer the question of whether there are ontological categories understood as the most general regions of reality. In what follows, I will first briefly touch on Aristotle's and Kant's doctrines of the categories to go on to advocate for Gustavo Bueno's philosophy of categorial closure, with 
his core idea that the scientific fields are but the categories, the main ontological regions.

\subsubsection{Aristotle's and Kant's Doctrines of the Categories}

Aristotle held that the question "what is it for something to be?" involved answering the question about "what is primary being?" In the Categories and the Topics, Aristotle presented a list of ten categories: ousia (substance, essence), quantity, quality, relative, where, when, being in a position, having, doing and being affected (Categories 1b25-2a4; Topics 103b21- 2. 3). Aristotle understood the categories as different ways of the predication of primary substances. Even based on its own assumptions, the structure of his table of categories was highly confused: the category of the substance (primary being) is completely different from the others since it is the ultimate (and essential) subject of predication. Notwithstanding, Aristotle asserted that substance, understood as essence, was also a predicate and, therefore, was a category since it could be predicated of itself. At any rate, being was not a genus with species, it lacked essence and definition and, consequently, the table was but an unfinished rhapsody (Metaphysics 998b23, 1059b31). Following a "linguistic" "Heideggerian" interpretation, Pierre Aubenque argued that Aristotelian categories were not divisions or parts of being, but rather modalities of the meaning of being, since they did not answer the question "in how many parts could "being" be divided?", but rather the more specific question "how many ways does "being" mean?" (Aubenque 1962). Kant himself sought to transcendentally deduce the table of categories from the structure of human understanding ( $K r V$ B95, 106; A70, 80). The pure forms of sensitivity of Kant's transcendental subject were a priori: space and time. The subject turned appearances into phenomena through the a priori pure concepts of understanding, which were the categories. Thoughts without content are empty and sensitive intuitions without concepts of understanding are blind. Sensitivity and understanding need each other because the senses cannot think and understanding cannot experience intuitions ( $K r V$ B75, A51). He distinguished four groups of categories based on quantity, quality, relationship and modality. Depending on the quantity, judgments could be universal, particular or singular, corresponding to the categories of unity, multiplicity and totality. Depending on the quality, judgments could be affirmative, negative or indeterminate, corresponding to the categories of reality, non-reality and limitation. Depending on the relationship, judgments could be categorical, hypothetical and disjunctive, corresponding to the categories of substance/accident, cause/effect and reciprocal action. Finally, he organized the categories of modality based on the three types of judgments: assertive judgments responded to the question of existence or inexistence, apodictic judgments to the question of whether something is necessary or contingent and problematic judgments to the question of whether something is possible or not.

It has been noted that the four types of categories proposed by Kant are Aristotle's first four categories, where the category of substance has been replaced by modality. John of St. Thomas deemed the first four Aristotelian categories as intrinsic_coming from substance itself-compared to the other categories that were extrinsic, as they came from outside substance. The Kantian theory of modality can 
also be coordinated with the three divine sciences in Spanish scholasticism. The realm of necessity is characteristic of the science of simple intelligence, the realm of existence of the science of vision and the realm of contingency and possibility of Molina's scientia media. Further, the a priori forms of Kant's sensitivity also correspond to Aristotelian categories: the coincidence of time is evident, while Kantian space roughly matches the Aristotelian category of place. The novelty of Kant's proposal can thus be better understood: Kant's unity of apperception may be coordinated with the scholastic divine understanding that has been secularized and makes use of space and time (which, for the Scholastics, were God's sensorium) and of the categories. Unlike Aristotle, understanding in Kant's philosophy determines being: human understanding is the dator formarum, just as God was the dator formarum in scholastic divine creation.

\subsubsection{Gustavo Bueno: "As Many Categories as Sciences"}

For Aristotle, there are as many sciences as there are genres since "a different science corresponds to a different genre" (Metaphysics IV, 2, 1003b19). As the categories are the ultimate genres in which existence occurs, Nichola Bonetti, in his Commentary on Aristotle's Metaphysica (1493), defended the existence of as many sciences as categories, even though Aristotle never explicitly drew this conclusion. Bonetti proposed 13 sciences: the science of the entity, the science of the infinite, the science of the finite and ten other sciences corresponding to each of the ten Aristotelian categories (Ramírez 1923, 11).

In his theory of categorial closure, Gustavo Bueno inverted this scholastic interpretation of Aristotle, holding that there are as many ontological categories as sciences. In his own words:

The best criteria that [...] I could use to determine the categories of being (that is, the radius of their respective circles), is based on analyzing the paths that lead from the categories of doing to the categories of being, namely, analyzing the processes whereby the sciences themselves are constituted. [...] Based on this idea, I distinguish as many ontological categories as closed sciences can be admitted following a critical-gnoseological analysis. (Bueno 1993, 602. My translation).

While the subjects' purposeful ends are necessary for the sciences, the contents of theorems and scientific principles do not depend on them when scientific fields are constituted. Sciences' theorems and principles cannot exist without the operations of the subjects or without the deployment of their purposeful goals; still, the related contents are not due to such operations or purposes but rather dictated by the results of their operations. The results of the operations are imposed on the subject, since they are immanent to the operated objects themselves. Although we need materials to build the house, the house results not from the materials but from the architect and builder. Here the "materials" of the sciences include the operations of the subjects and their phenomenological moments. The principles and theorems, though, are not due to these subjective moments of scientific construction but to the actual 
structure of what is real. A science's theorems and the principles coordinating them organize the scientific category and account for the structure of what exists. Scientific categories strictly define the "necessary", which is the strongest form of coexistence, and thus shape "stubborn reality".

Interpreting the sciences as ontological categories goes back to the philosophies of Auguste Comte and Edmund Husserl, even though neither of them were fully aware of the related consequences. Auguste Comte called the six key sciences "categories": mathematics, celestial mechanics, terrestrial mechanics, chemistry, biology and social physics (Discourse on the Positive Spirit II, 1, paragraph 19). Comte realized that it was not possible to reduce those sciences to one, despite his advocating for a system of sciences (Comte 1903). Edmund Husserl also referred to sciences as ontological (ontological-material) categories. For Husserl, scientific principles and laws are materially determined, synthetic, essential truths and are always regional (Ideas Pertaining to a Pure Phenomenology and to a Phenomenological Philosophy 16-17).

The fundamental modes of being to which I have referred in the third section of this paper take specific material form in the contents of the different categories: physical necessity, logical possibility, historical contingency, etc. The fact that coexistence is a non-connected universal relationship entails existing disconnections and the perceived discontinuities between the categories. An example is given in the meteorite that wiped out the dinosaurs; as a deterministic phenomenon from an astrophysical point of view, when influencing biological processes it acted as an extra-biological cause of mass extinction. Although we recognize astronomical and biological determinism in each category, the relationship between the phenomena of the different categories does not necessarily obey categorial principles.

\subsubsection{The Two Orders of Categories}

As David Alvargonzález has argued, there is no system of sciences and, therefore, no system of ontological categories (Alvargonzález 2019a). Moreover, categories cannot be integrated within one single category, since there is no single unified science, one encompassing all sciences. However, following Gustavo Bueno, I defend the existence of two different orders or categories, depending on the degree to which the subjects' operations are segregated. Bueno calls them "categories of being" and "categories of doing" (Bueno 1993, 222-236). The former correspond to the formal and natural sciences, while the categories of doing (which also include the categories of making) notably include the techniques, the technologies and the social or cultural sciences. Rephrasing Bueno's distinction, I assert that his "categories of being" are ananthropic, while his "categories of doing and making" are anthropic: the former segregates the subjects' purposeful ends while the latter necessarily involves a purposeful teleology (Bueno 1993, 594 et seq.). Regarding the ananthropic categories, there are necessary relationships between things and processes independent of the subjects and regulated by scientific principles and theorems, while purposeful goals regulate the anthropic categories. Practical purposes regulate the anthropic categories, which may in turn maintain subordinate relations among them, such as when a technical or technological category serves specific 
political, legal or military purposes. In the anthropic categories (those Bueno calls categories of doing and making), the rhapsody of the productive (poietic) and practical categories refers to the field of philosophical anthropology rather than that of ontology. At any rate, one cannot lose sight of the fact that doing, and in particular human doing, is a characteristic mode of coexistence and codetermination and, consequently, a specific mode of being. This is the reason why I prefer to speak of anthropic and ananthropic categories. Ethology, sociology and anthropological categories cannot sit on the sidelines of ontology. Insofar as it refers to totalities with codetermined parts, the idea of system (as David Alvargonzález defined it in Alvargonzález 2019b) can contribute to establishing analogies between ananthropic codeterminations (typical of the sciences) and anthropic codeterminations (typical of techniques and technologies), between the orders of categories labelled by Bueno as categories of being and doing.

As distinguished above, the fundamental modes of being are present both in the ananthropic and the anthropic categories. Both strict sciences and human activities organized around practical purposes involve the simultaneous operation of several fundamental modes of being: past, present and future.

The necessary mode of establishing connections and disconnections between existing things and processes occurs in a particularly rigorous way in the theorems and principles of the strict sciences that constitute the order of the ananthropic categories. However, the modes of necessity and impossibility can appear as something practical and anthropic prior to the sciences existing. There are practical contexts making something necessary or impossible since humans, in realizing their projects, establish practical priorities and differentiate what is necessary from what is expendable. When pursuing a specific practical purpose, a person has to evaluate what is necessary for that purpose as opposed to what is accessory. The state of the art at any given time can make certain purposes impossible, even if they are not impossible in a scientific, abstract sense, as seen over millennia with manned flight. I thus contend that the fundamental modes are transcendental to the two orders of categories. The distinction between the real and the fictional is also present prior to the existence of the strict sciences; when applied to the sciences, it makes it possible to differentiate real science from science fiction.

Once again, Aristotle's famous distinction between speculative and practical disciplines precedes the two orders of categories. He distinguished the rational powers of crafts, arts and techniques, which act through desire and choice and can produce contrary effect, from the irrational powers, which cannot produce contrary effects and act necessarily (the hot can only heat) (Metaphysics IV, 6, 1010b35; VII, 17, 1041a; VIII, 5, 1044b10); we would call these powers "propositive" and "non-propositive", respectively. Throughout the Metaphysics, Aristotle posited the ananthropic character of certain regions of reality studied by speculative disciplines, which we now identify as the strict sciences (Metaphysics VII, 17, 1041 a1-5; VIII, 5, 1044b10; IX, 2, 1046b1-20).

The ontological ananthropic categories are dissociable, yet the conditions for separation are highly specific. It should first be recognized that the fields of science are involved in each other like swords in combat: each scientific field, like each army, follows its own principles and theorems and has its own rhythm, thus 
making it possible to disassociate each field. However, the lack of separation between the ananthropic categories is asymmetric. The principles and theorems of the physical category are intelligible as independent, separate and even prior to the biological category, but not vice versa, since every biological organism is at the same time a physical object. A significant portion of the biological category is possible without direct reference to the behavioral categories, but not vice versa, since behavior is exclusive to animals that are biological organisms. Behavioral categories can be understood without historic-anthropological categories, but not vice versa since the latter are impossible in the absence of behavior. A metaphysical version of this asymmetric relationship between categories was already put forward by Aristotle in De anima and was followed by Aquinas in Summa Theologiae (I, q.96, a.2).

\section{The Dimensions of Being and Classification Thereof}

As stated in the first section, existence involves coexistence and the codetermination of certain things and processes by others. Therefore, the dimensions of the existing are the different components, moments or aspects distinguished in situations of codetermination and coexistence. As I have argued in the second section, the main criterion for establishing the difference between dimensions and modes of being is that dimensions, as with the dimensions of Euclidean space, are dissociable but not separable, while the different modes of existence can be relatively separated under the conditions discussed above.

Operating on these assumptions, there are two types of dimensions of the existing, depending on whether we intend to analyze configurations or processes. In the former case, we make an abstraction of time, while in the latter, we directly take into account the transformations defining the different times.

\subsection{The Configurational Dimensions of Being}

Since its inception as a discipline in Aristotle's metaphysical books, ontology has been tasked with determining the minimum core components of the existing. It is thus naive to claim any originality when presenting any proposal in this connection. Here, though, my purpose is not to expound on an original discovery but rather to illustrate the correspondence between certain philosophies and argue for interpreting the components of the existing as configurational dimensions, once their inseparability has been admitted. I contend that when philosophers presented these components as separate substances, parts, worlds, domains, kingdoms, phases or genres, they engaged in a substantialization of ideas similar to that of Plato's separate forms. I then present a heterogeneous sampling of historical references to show the ubiquity of specific ontological ideas throughout the history of philosophy. Lastly, I take a 
systematic point of view to discuss the reformulation of these ideas in a manner appropriate to the state of the present world.

\subsubsection{Historical References}

Considering existence as coexistence means that configurations and processes must coexist with human subjects in a more or less immediate fashion, which is the main reason why the dimensions of being bear unavoidable epistemological significance. For our purposes, I posit that human subjects have been relatively stable from the beginning of philosophy in Greece, which explains why, in the history of philosophy, there are specific ideas that repeatedly crop up in the core of the most varied philosophical systems.

While not exhaustive, Table 1 illustrates some of the correspondences between the ontological ideas of different authors. Starting with the origins of ontology as an academic discipline, in the Metaphysics Aristotle substantialized the contents of consciousness and the abstract by assuming that two different kinds of substances exist: the sensible and the intelligible (Metaphysics XI, 1, 1959b). Mathematical substances (immovable and not separated) are a third middle kind. Aristotle's detached God is the paradigm of pure intelligible, separated substance. The radical ontological difference between the individual, eternal, separable soul and the corruptible body represented a central principle in all of Christian philosophy. In this Christian vein, in his Principles of Philosophy ([1644] 1983) Descartes defended the existence of two types of things - the res extensa and the res cogitans - and located the intelligible in his idea of God, which he understood as a guarantor of mathematical truths. For Descartes, in human beings the pineal gland was the seat of a mysterious connection between the body and the soul. Critiquing Descartes, Spinoza redefined the idea of God as a plural substance endowed with infinite attributes of which we only have knowledge of extension and thinking. Spinoza's intelligible attributes have been identified as the modi cogitationis, as the thoughts "in God", which are essential, causal and eternal (Spinoza 1985; Peña 1974). Spinoza defines the substance attributes as "what the intellect perceives of a substance as constituting its essence" (Ethics, def. 4) so there is room to find that the attributes of extension and thinking are more an epistemological than an ontological separation. In this case, Spinoza's attributes would be close to what I call "dimensions". Rudolph Carnap clearly defended the existence of three types of objects (physical, auto-psychological and hetero-psychological), most certainly understanding them as ontologically different and enabling a separate existence (Carnap 1928 and 1950).

Certain philosophers reflected the ontological structure of the world in distinguishing the different parts of philosophy. The Stoics divided it into three higher disciplines: physics, ethics and logic. Within the Christian tradition, Christian Wolff distinguished between the world, the soul and God (the three ideas that Kant declared transcendental illusions), assigning a discipline to each of those parts of ontology: rational cosmology, rational psychology and rational theology (Wolff 1720). Hegel was responsible for historicizing the parts of ontology by turning them into phases in universal history: nature, spirit and idea (Hegel 1817, 1827 and 1830). In this, the temporal continuity of his phases was compatible not only with their 


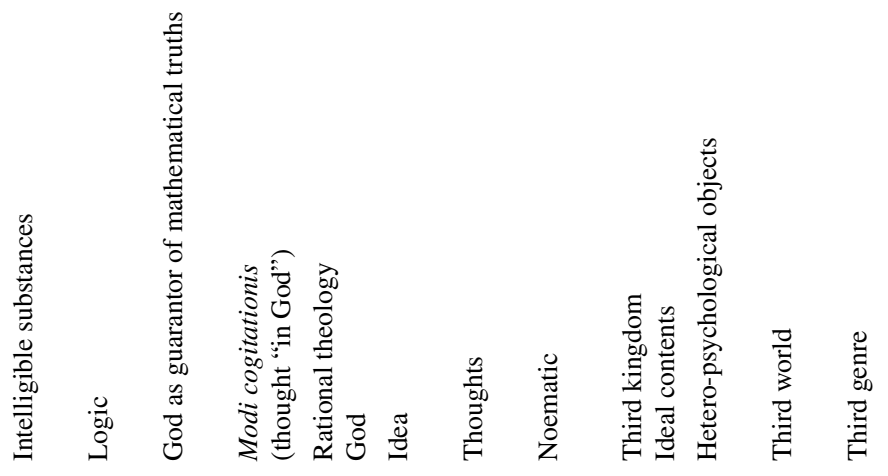

范

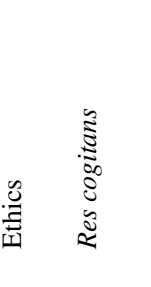

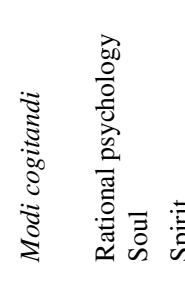

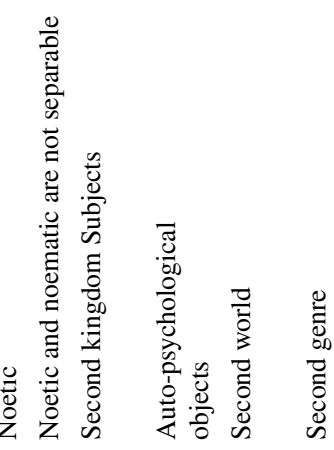

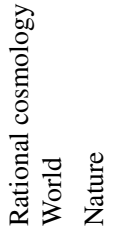


dissociation but also with consideration of the three dimensions (natural, spiritual, and ideal) in each of the phases. Frege, Simmel, Popper and Bueno divided reality into three regions they respectively called domains, kingdoms, worlds and genera: objects always reside in the first; the second contains subjective representations and the contents of consciousness; and the third accommodates abstract concepts, especially logical and mathematical concepts (Frege 1956; Simmel 1910; Popper 1968 and 1978; Bueno 1972). "Kingdom", "domain" and "genus" are words that take on precise meaning as concepts in biological taxonomy. In all three cases, even when this taxonomy has phylogenetic foundations, it seems possible to interpret these regions as relatively separate. In Popper's worlds, this separation is explicit, although Popper adds an ad hoc principle whereby the relations between the first and the third world must always take place through the second. Bueno's critiques of Simmel's and Popper's theories and certain texts in Ensayos materialistas (Bueno 1972) permit an interpretation of Bueno's genera of materiality as ontological dimensions.

Edmund Husserl's distinction of the three moments of phenomenological perception - the hyletic, the noetic and the noematic - and his postulate of the inseparability of the latter two are closer to the idea of inseparable dimensions that I am advocating here (Husserl 1913). This can also be seen when Bueno interprets his theory of the genera of materiality from what he calls the semantic dimension of science, with its three moments: physicalist, phenomenological and essential (Bueno 2013). Table 1 summarizes the correspondence between the ideas of these philosophical systems.

\subsubsection{Systematical Perspective}

Throughout the history of philosophy, many philosophers have stressed the importance of distinguishing these three regions of reality and have underlined their mutual irreducibility. I assume that the contents of consciousness cannot be entirely reduced to physicalist processes and that psychology cannot be entirely reduced to physiology or neurology. I also assume that abstract contents cannot be reduced to psychological processes and that, therefore, mathematics and theoretical physics cannot not reduced to psychology. The metaphysical version of such irreducibilities crops up in Christian philosophy, which posits an eternal soul's separate, post-mortem existence.

I hold that these three regions are not separate regions, kingdoms or worlds but rather the three dimensions that are present in everything existing. This involves postulating that any existing being has a physicalist, phenomenological and essential dimension such that these three aspects do not lead to three modes of being that are independent of each other but to three dimensions of an ontological space arising in the analysis of different beings. This interpretation runs parallel to the idea that none of these regions is the most radical or fundamental, as that would entail a slip into the different varieties of reductionism: physicalist, naturalist reductionism; the reductionism of subjective idealism; and the idealist reductionism.

These dimensions have frequently been interpreted as modes of being: universals as a mode of being real (universals are real); the psychological, private world as a mode of existing, of being (moods are realities); the corporeal world 
as a modality in the existing (physicalist objects are realities). However, given the inseparability of the three regions, interpreting these dimensions as modes leads to substantializing each one of them, as if there was a subjective way of existing separately from objects, and the same with all other modes. I assume that these dimensions of the existing are irreducible, but also inseparable, even though they are dissociable for the purposes of analysis, as in the dimensions of Euclidean space.

It is possible to think about a past world in which animals and human beings did not yet exist, and in which there would still be no contents in the region of consciousness. However, that past world exists as a sui generis mode of being since it exists only insofar as it is present in today's world. The dimensions of being involve the subject: when the subject is absent, we assume that reality continues existing, coexisting and codetermining, but it can no longer be ordered based on those dimensions and sinks into the darkness where "all cats are grey". Only those parts that are "enlightened" from the present appear organized in those dimensions as a result of the sciences, which are the categories of being that enable us to refer to a pre-biotic, pre-anthropic reality.

Confusing modes and dimensions of being has led to major misunderstandings throughout the history of philosophy. I will briefly deal with the contradistinction between essence and existence, holding that essential, abstract contents do not oppose the existing, but define themselves in the face of phenomena, appearances and objects. The existing does not oppose the essential but rather the inexistent, whether it is a necessary inexistence (the impossible) or a contingent inexistence. For this reason, I do not believe that the modes of being are "being by essence" or "being by existence". Existence involves essence since, as Plato stated, even mud, dirt and hair have essences (Parmenides, 130a-e). At any rate, the degree of existence of the different essences must be discussed since an essence without existence is an idealist construction, a substantialization, a hypostasis and a fiction. Thus, the essential components of any existing being are not completely separable from the subjective and the objective.

The ontological argument (Anselm, Descartes, Leibniz) seeks to derive God's existence from his essence, by treating existence as if it were one more separable attribute, a supposition that Kant had already critiqued. In his seminal existentialist lecture "Existentialism is a humanism", Sartre defended the inversion of the relations between essence and existence typical of the ontological argument (Sartre 1956). For Christian philosophy, the essence comes first and existence derives from it, whereas for existentialism, existence is primitive and essence is defined from existence. Sartre flipped the relationship around (existence determines the essence, not vice versa), but he failed to change the frame of thought, which in my view is false, of a separate essence and existence. I contend that essence is not a mode of being: it is neither categorial nor is it a fundamental mode. Essence affects several categorial modes (mathematical, physical, biological, anthropological essences) and several fundamental modes of being since it affects present-day, past and future being with all its variants and even affects the fictional mode of being. It thus seems necessary to recognize that essence is a dimension 
of everything existing since we understand existence as coexistence with the epistemological subject.

\subsection{The Processual Dimensions of Being: Hylomorphism}

As already stated, the dimensions of being are certain aspects or components of existing configurations and processes that are dissociable for study even though they are inseparable. In the previous section, I distinguished phenomenological, objectual and essential or abstract components in any existing configuration. In this section, I discuss the dimensions of the transformation processes. Defining existence as coexistence and codetermination, in this paper I have thus implied that the existing is always in a process of continuous transformation, even in those cases in which there is stable dynamic equilibrium, which gives rise to identical transformations.

Analyzing change processes requires reference to the matter being transformed and to the form guiding the transformation and, therefore, a judgment must be made about the significance of hylomorphic theory. I will first deal with hylomorphism as it appears in Aristotle's philosophy and then briefly discuss the extent to which hylomorphism is compatible with the state of the present world.

\subsubsection{Aristotelian Hylomorphism}

Aristotle's hylomorphic theory asserts that all substances in the world are a compound of matter and form. In this, Aristotle thus rejected the existence of pure, separate forms and put distance between his theories and those of his teacher Plato. Heavenly bodies remain material; nevertheless, they are made up of very subtle matter (the ether), which makes them incorruptible and, to a certain extent, divine, and the mathematical entities are not separated from the sensitive (Metaphysics XIII, 2, 1077b12; XIV 3 1090a 30; XIV, 6 1093b 25).

Therefore, it clearly seems that Aristotle held that matter and form were dissociable but inseparable. Jonathan Lang finds that the Aristotelian form is but the formal determinant of a given transformation, the agent of change, the hylomorphic compound that directs the change of another (Lang 1988; Aristotle, Physics III, 2, 202a911). In techniques, the artisan is the "agent of change" and, in practical disciplines, the learning processes are responsible for transmitting the forms. Living organisms, on the other hand, change themselves, they are "automotive" or "autochangers" and, in them, the forms are transmitted by reproduction (Physics II.8, 199b32-33). Distinguishing a material cause other than a formal cause is another way of distinguishing what is being transformed from what regulates or determines the transformation (Metaphysics I, 3, 983a25-983b; V, 2, 1013a25-1013b).

Aristotle's theory of matter and form refers to the ideas of actuality and potentiality, to the idea of substance and to the idea of God. He identified actuality with form and potentiality with matter and advocated for the primacy of actuality (and of form) as opposed to potentiality (and matter): Nothing is transformed (moving from potentiality to actuality) without a formal determinant that is already a prior substance in actuality (De anima 412a10; Metaphysics 1048a33-35). At any rate, in Aristotle's 
philosophy, actuality and potentiality are not dimensions of being, although they are modes of being, since something existing can be either in actuality or in potentiality. However, the extent to which Aristotle holds form and matter to be separable is not clear. This separation is evident in the metaphysical, Judeo-Christian creationist philosophy where pure souls and spirits are understood as matterless forms, such as the incorporeal living angels.

\subsubsection{Matter and Form as Dimensions of Change}

In this paper, I operate on the assumption that any totality and configuration of the world is processual. Time can be abstracted, but it can never be wholly eliminated, such that seemingly timeless realities should be interpreted as processes remaining in dynamic equilibrium. Accordingly, given a certain context, an entity fulfills the function of matter when it is what is transformed and fulfills the function of form when it determines the transformation.

The idea of transformation and the ideas of matter and form remain present in every kind of mode that I have put forward in the third section of this paper, which strongly suggests that they relate to the dimensions of being:

1. In the fundamental modes, a distinction should be made between necessary, contingent and possible transformations. The idea of purpose makes it possible to internally (and not metaphysically, as in Aristotle) connect matter and form with the ideas of actuality and potentiality: actuality and potentiality are modes of being, whereas matter and form are dimensions of any transformation and codetermination of the real. In my view, the correspondence Aristotle sets up (actuality as form, and potentiality as matter) in certain texts confuses modes (actuality, potentiality) and processual dimensions (matter and form) (De anima 412a10; Metaphysics 1048a33-35).

2. In the categorial orders of being, ananthropic transformations, regulated by scientific laws and principles, can be distinguished from anthropic transformations (of the order of doing and making) regulated by goals. The modalities of finality are but ways of classifying these transformations and, consequently, of classifying the modes of being of processual totalities. In both cases (anthropic and ananthropic transformation), the distinction between matter and form serves to differentiate what undergoes the transformation from what controls it.

Aristotle posited that the substances of the world (the hylomorphic substances) are composed of matter and form. Form provides the compound its essence and unity, whereas matter is responsible for individuation. Nevertheless, as used today the distinction between form and matter is useless to gaining an understanding of the unity or identity of substances, structures, aggregates or systems, which are always composed of multiple parts and determinants. In my view, the current distinction between matter and form only serves to account for different moments or dimensions of dynamic balances. 


\section{Contributions}

In this paper, I have assumed the following:

1. Philosophical ideas always have practical sources.

2. The philosophical idea of being is Greek in origin.

3. Aristotle's idea of being has metaphysical components.

4. The metaphysical accretions can be stripped from this idea.

5. The idea of existence, defined as the coexistence and mediated or immediate nonconnected codetermination of objects and processes, is not metaphysical and is structured as a general abstract function with different modes.

Based on these assumptions, I have put forward a distinction between modes and dimensions of being, classifying the different modes of being into two groups:

1. The fundamental modes of the idea of being are determined by the different values taken by the mutual, non-connected determination of objects and processes: the present, in opposition to the past and the future (with their possible and potential variants); the necessary, in opposition to the contingent; and the real, in opposition to the fictional.

2. The categorial modes of the idea of being are the categories. I have argued that there are two orders of categories: categories of being and categories of doing. I contend that the strict sciences are the categories of being. The categories of doing are a sui generis mode of being referring to the ontological scope of purposeful goals.

I have also proposed a classification of the different dimensions of being:

1. Everything existing involves physical, phenomenological and essential components that are dissociable, but not separable. I have proposed interpreting these components as configurational dimensions of the idea of being.

2. I have also proposed interpreting the ideas of matter and form as two procedural (functional) dimensions or moments of any transformation: matter is the subject of transformation while form controls the transformation. As with the configurational dimensions, matter and form are dissociable for study, but are not separable.

Funding Open Access funding provided thanks to the CRUE-CSIC agreement with Springer Nature.

Open Access This article is licensed under a Creative Commons Attribution 4.0 International License, which permits use, sharing, adaptation, distribution and reproduction in any medium or format, as long as you give appropriate credit to the original author(s) and the source, provide a link to the Creative Commons licence, and indicate if changes were made. The images or other third party material in this article are included in the article's Creative Commons licence, unless indicated otherwise in a credit line to the material. If material is not included in the article's Creative Commons licence and your intended use is not permitted by statutory regulation or exceeds the permitted use, you will need to obtain permission 
directly from the copyright holder. To view a copy of this licence, visit http://creativecommons.org/licen ses/by/4.0/.

\section{References}

Abbott EA ([1884] 2017) Flatland: A Romance of Many Dimensions. Kansas, USA: Digireads.com Publishing

Alvargonzález D (2019a) La clasificación de las ciencias desde la filosofía del cierre categorial. Revista De Humanidades 37:99-126

Alvargonzález D (2019b) Sciences as systems. Perspect Sci 27(6):839-860

Aubenque P ([1962] 2013). Le probleme de l'être chez Aristote. Paris: Presses Universitaires de France

Bueno G (1972) Ensayos materialistas. Taurus, Madrid

Bueno G (1993) Teoría del cierre categorial t.2. Pentalfa, Oviedo

Bueno G (2010) El porvenir de la filosofía en las sociedades democráticas (1). El Catoblepas 100:2

Bueno G (2013) Sciences as categorical closures. Pentalfa, Oviedo

Carnap R (1950) Empiricism, semantics an ontology. Rev Int Philos 4:20-40

Carnap R ([1928] 2003) The logical structure of the world. Chicago: Open Court Classics

Comte A ([1844] 1903). A discourse on the positive spirit. London: W. Reeves

Descartes R ([1644] 1983). Principles of philosophy. Dordrecht: Reidel

Frege G ([1918-1919] 1956). The thought: a logical inquiry. Mind 65/259: 289-311

Hegel GWF ([1817; $\left.18272^{\text {aa }} 18303^{\mathrm{a}}\right]$ 1974, 2004, 1970). The Encyclopaedia of the Philosophical Sciences. Oxford: Oxford University Press

Husserl E ([1913] 2001) Ideas pertaining to a pure phenomenology and to a phenomenological philosophy. New York: Springer Verlag

Kant I ([1781, 1787] 2007). Critique of Pure Reason. London: Penguin Books

Lang J (1988) Aristotle. The desire to understand. CUP, Cambridge

Mumford L (1934) Technics and civilization. Harcourt, Brace \& Company, New York

Peña V (1974) El materialismo de Spinoza. Ensayo sobre la ontología spinozista. Revista de Occidente, Madrid

Popper KR (1968) On the theory of the objective mind. In Popper KR (1972) Objective Knowledge: An Evolutionary Approach, pp.153-191. Oxford: Oxford University Press

Popper KR (1978) Three worlds. The tanner lecture on human values. Delivered at the University of Michigan on April 7, 1978

Ramírez S (1923) De ipsa philosophia in universum, secundum doctrinam aristotélico-thomisticam. Ciencia Tomista 28

Sartre JP ([1946] 1956) Existentialism is a Humanism. New York: World Publishing Company

Schütz A (1932) Der sinnhafte Aufbau der sozialen Welt: eine Einleitung in die verstehende Soziologie. J. Springer, Wien

Schütz A ([1962] 2008) The Problem of Social Reality. Netherlands: Kluwer

Simmel G (1910) Hauptprobleme der Philosophie. Göschen, Leipzig

Spinoza B ([1677] 1985) Ethics. Princeton: Princeton University Press

Stace WT (1935) Metaphysics and meaning. Mind 44(176):417-438

Toulmin S (1958) The uses of argumentation. Cambridge University Press, Cambridge

Wolff C ([1720] 2009). Rational Thoughts on God, the World and the Souls of Human beings: Also all Things in General. In Eric Watkins (eds.) Kant's Critique of Pure Reason: Background Source Materials. Cambridge University Press

Publisher's Note Springer Nature remains neutral with regard to jurisdictional claims in published maps and institutional affiliations. 